\title{
ALFABETIZAÇÃO E NOVAS TECNOLOGIAS, UMA ANÁLISE CRÍTICA SOBRE UMA SEQUÊNCIA DIDÁTICA APLICADA A SÉRIES INICIAIS
}

\author{
LITERACY AND NEW TECHNOLOGIES, A CRITICAL ANALYSIS ON A \\ TEACHING SEQUENCE APPLIED TO INITIAL SERIES
}

\author{
Danielle de Almeida Moreira Cande Martins \\ Professora de Ciências e Biologia no CSA Leblon. \\ Professora de Empreendedorismo e Projeto de Vida no ND Recreio. \\ https://orcid.org/0000-0002-1174-0974 \\ Rodrigo José Penha Martins \\ Coordenador e Professor do Curso de Tecnologia do Senac Rio. \\ https://orcid.org/0000-0001-5903-0624
}

Ana Lúcia Mendes Vital

Professora de Filosofia da Fundação de Apoio à Escola Técnica do Estado do Rio de Janeiro. https://orcid.org/0000-0001-7665-2898

\section{Ana Paula Legey de Siqueira}

Pesquisadora Colaboradora na área de Divulgação Científica no Instituto de Engenharia Nuclear.

Professora no Centro Universitário Carioca. Pós Doutora em Divulgação Científica (IEN/CNEN). https://orcid.org/0000-0002-9056-9844

André Cotelli Espírito Santo

Colaborador de Projetos no Instituto de Engenharia Nuclear. Professor no Centro Universitário Carioca. Mestre em Ciência e Tecnologia Nucleares pelo IEN. https://orcid.org/0000-0002-6593-5259

Antonio Carlos de Abreu Mól

Pró-Reitor de Ensino na Comissão Nacional de Energia Nuclear. Pesquisador INCT. Professor no Centro Universitário Carioca. Doutor em Engenharia Nuclear pela COPPE/UFRJ.

https://orcid.org/0000-0002-1744-1692

Victor Gonçalves Gloria Freitas

CEO na AresVR. Professor no Centro Universitário Carioca. Doutor em Engenharia Nuclear pela COPPE/UFRJ. Mestre em Engenharia de Reatores pelo Instituto de Engenharia Nuclear. http://orcid.org/0000-0002-0154-606X

Data de submissão: $25 / 11 / 2019$

Data de aprovação:16/01/2020

\section{RESUMO}

O presente artigo apresenta um levantamento bibliográfico acerca do uso de Tecnologias Digitais de Informação e Comunicação (TDICs), na alfabetização, bem como uma análise crítica da aplicação de uma sequência didática seguindo as orientações e informações coletadas na literatura pesquisada. Os pesquisadores atuam como docentes em áreas direta e indiretamente ligadas ao curso de alfabetização, porém, todos são pesquisadores em novas tecnologias na educação, o que faz com que o objeto de pesquisa deste trabalho tenha sido bastante articulado com a prática de uma pedagogia de maior sintonia com o século XXI, buscando promover um aprendizado mais motivado, empático e colaborativo, em uma turma de alfabetização fora da faixa de idade padrão.

Palavras-chave: Alfabetização. TDICs. Sequência didática. 


\section{ABSTRACT}

This paper presents a bibliographic survey about the use of Digital Information and Communication Technologies (DICTs) in literacy, as well as a critical analysis of the application of a didactic sequence following the guidelines and information collected in the researched literature. Researchers act as teachers in areas directly and indirectly linked to the literacy course, but all are researchers in new technologies in education, which makes the research object of this work have been very articulated with the practice of a pedagogy of more in tune with the 21 st century, seeking to promote a more motivated, empathic and collaborative learning in a literacy class outside the standard age range.

Keywords: Literacy. DICTs. Didactic sequence.

\section{INTRODUÇÃO - UMA REFLEXÃO ACERCA DA ALFABETIZAÇÃO E AS TDIC'S}

Para apresentar uma reflexão sobre o processo de alfabetização, apoiamo-nos nas concepções da pesquisadora Emília Ferreiro (1998), orientanda de Jean Piaget outrora, Alfabetização em processo, em suas referências ao papel da escola de alfabetizar e letrar a criança, tendo a consciência de que este processo não é simples e que a criança precisa de tempo para correlacionar a compreensão da escrita ao seu uso funcional.

O contexto social no qual a criança está imersa no momento é de extrema importância, visto que leitura e escrita caminham juntas e correspondem a um processo no qual os envolvidos precisam de motivação para executá-lo com uma perspectiva promissora. Sentir ou mesmo perceber a necessidade de aprender é o primeiro passo a ser considerado na visão de Ferreiro (1998) para que o conhecimento possa vir a ser estruturando. Assim, o professor em sua prática pedagógica precisa ter ciência do nível do conhecimento em que seu o aluno se encontra para estimular sua aprendizagem, bem considerar todo o universo sociocultural que faz parte do cotidiano daquela criança.

Pensando nas abordagens e métodos que se utilizam para trabalhar a alfabetização, como a ludicidade, por exemplo, há de se considerar que até os anos 1990, as crianças brincavam nas ruas em atividades que expressavam movimento, socialização e estratégia. Com o surgimento massivo das tecnologias as crianças passam a ter uma vivência cada vez maior com jogos digitais e diferentes aplicativos, que passam não só a alterar a forma de brincar, mas também de enxergar e se expressar neste mundo. De acordo com Ana Teberosky (2003, p. 31), em seu texto Aprender a Ler e a Escrever: "Com a difusão do uso da informática, entramos em uma nova etapa cultural: a era digital. Essa realidade não passa despercebida às crianças".

A alfabetização é uma etapa onde essas influências precisam ser levadas em consideração para o desenvolvimento de uma aprendizagem significativa. O psicólogo Ausubel, em suas diferentes proposições na década de 60, descrevia que o objeto de aprendizagem que se pretende desenvolver precisa conectar-se a algo já conhecido, caso contrário a aprendizagem se faz mecânica. Neste caso, o estudante passa somente a decorar e em poucos dias tende a esquecer o que aprendeu.

O que se percebe na escola hoje, ainda é uma presença discreta dessas tecnologias, inerentemente parte significativa do universo de milhares de crianças, jovens e adultos nos dias atuais, em metodologias ligadas a diferentes processos pedagógicos, inclusive nos processos que levam à alfabetização do estudante.

Por tanto, de forma significativa, o objetivo geral deste trabalho consiste em, a partir de um levantamento bibliográfico acerca dessas carências metodológicas, fazer uma análise crítica da aplicação de uma sequência didática que utilize TDICs como 
proposta, partindo do pressuposto de que esta estaria mais adequada às demandas educativas contemporâneas. O problema que se examinou tratou do aprendizado de crianças na alfabetização, em uma turma fora da faixa de idade padrão.

\section{REFERENCIAL TEÓRICO}

Como agentes ativos de seu processo de aprendizagens, as crianças de hoje veem o lúdico de outra maneira, executam tarefas de forma diferente, portanto espera-se que os envolvidos no processo de ensino-aprendizagem considerem estes aspectos ao planejar e promover atividades pedagógicas.

Para Ferreiro (1999), à "medida que as crianças são estimuladas e avançam no processo de alfabetização, suas hipóteses vão variando conforme são superadas"; a "escrita do próprio nome da criança é o primeiro passo, pois abre caminho para a exploração de conceitos como a identificação das letras, quantidade de letras, letra inicial e sua relação com outras palavras, dentre outros aspectos que também podem ser trabalhados". Porém, para as crianças, o primeiro contato com a língua escrita não se faz na escola, mas em todo lugar em que ela permeia e com as Tecnologias Digitais de Informação e Comunicação, as TDICs (O termo 'TDIC' tem como significado 'Tecnologias Digitais de Informação e Comunicação'. Começou a ser muito usada em 9 de abril de 1997, quando o Ministério da Educação, realizou um projeto chamado 'Prolnfo' (Programa Nacional de Tecnologia Educacional) promovendo o uso das tecnologias na educação para a melhoria do ensino); desde muito jovens, já interagem com as palavras que estão ali na palma de suas mãos, por longas horas do dia. Logo, a criança, segundo Ferreiro:

(...) percebem a escrita com um conjunto de formas arbitrárias, dispostas linearmente, que não representam os aspectos figurais do objeto. Por isso temos que considerar tudo que a criança seja capaz de fazer e utilizar suas produções para compreender o que se quis expressar, já que a aquisição da leitura e da escrita não é um processo automático que acontece de forma igual em todas as crianças (FERREIRO, 1993, p. 84).

Torna-se indispensável, segundo Ferreiro (1998), refletir sobre as diferentes metodologias já utilizadas, uma vez que a leitura e a escrita não são processos indissociáveis, mas se complementam para a compreensão do sistema de escrita. A partir do universo das TDICs e da cultura digital, é possível oferecer condições bem mais atraentes e situadas para que as crianças se apropriem da linguagem e de suas funções sociais, ensejando também novas formas de letramento.

Thaís Cristina Tezani, em seu artigo Nativos digitais: considerações sobre os alunos contemporâneos e a possibilidade de se (re)pensar a prática pedagógica, afirma que:

Nossos alunos estão imersos num contexto digital. Inseridos em uma sociedade digitalizada na qual as TDIC estão presentes na organização e no funcionamento da vida cotidiana, indagamos sobre seu uso no processo de ensino e aprendizagem: Como (re)pensar a prática pedagógica diante das especificidades dos nativos digitais? (TEZANI, 2017, p.61).

Ainda se destacam, segundo Tezani (2017), as TDICs, que, para a academia, são consideradas como "instrumentos mediadores, já que a aprendizagem e o ensino são formas universais de desenvolvimento mental". Pode-se expressar essa ideia de duas maneiras: "a) enquanto o aluno forma conceitos científicos, incorpora processos de pensamento e vice-versa; b) enquanto forma o pensamento teórico, desenvolve ações mentais, mediante a solução de problemas que suscitam a atividade mental do aluno". 
A proximidade das crianças do século $X X I$ de recursos tecnológicos oferece, a partir de uma grande variedade de possibilidades - como jogos interativos nos dispositivos móveis, vídeos e clipes musicais oferecidos ao público infantil na web, entre outros - oportunidades para o profissional de educação explorar formas de realizar esta mediação. Assim sendo, pode-se ressaltar, de forma a corroborar o que até aqui foi mencionado, a teoria sócio-histórico-cultural Vygotskyana. Nesta teoria, tem-se que o indivíduo não se constrói aquém da sociedade, mas sim de forma direta às suas interações com ela, de forma recíproca, considerando sua cultura e sua história de vida, o que também inclui as situações de aprendizagem, as oportunidades e todas as interferências externas e internas na qual ele se expôs ao longo da vida. Então, segundo Lev Semenovich Vygotsky, em sua obra Pensamento e Linguagem, o discente assimila o conhecimento teórico e as capacidades e habilidades relacionadas a esse conhecimento, mediado pelas TDICs.

Para Larisse Santiago (2016), em sua pesquisa $O$ uso das Tecnologias Digitais na busca da superação do analfabetismo, ter acesso às tecnologias digitais de informação e comunicação (TDIC), principalmente se houver dispositivo com acesso à Internet ou a aplicativos adequados à faixa etária, é um fator de inclusão digital, e as crianças estão tendo contato com essas ferramentas desde a tenra idade. Tais tecnologias abrem um leque de possibilidades para o desenvolvimento de novas práticas educativas digitais.

De acordo com Soares (2002) a tela torna-se um novo espaço de escrita que traz significativas mudanças nas formas de interação do escritor com o leitor, do escritor com o texto, do leitor com o texto e até mesmo do ser humano com o conhecimento. (SANTIAGO, 2016, p.12)

A utilização de jogos, aplicativos e softwares educativos na construção de sequências didáticas ou mesmo de materiais educativos voltados para os processos de ensino e de aprendizagem, no que se refere à aquisição da escrita e da leitura, contribuem para o processo de alfabetização infantil, conforme Wládia Moreira, em sua dissertação de mestrado Análise de Software Educativo para Alfabetização de crianças (MOREIRA, 2014, p. 37). As experiências vividas durante a aquisição do letramento digital podem motivar as crianças a compreenderem e interpretarem o sistema alfabético, abrindo um caminho mais fácil, interessante e mais concreto para o letramento impresso. A ideia não é diminuir ou desconsiderar a cultura do impresso, mas ressignificar o objeto da leitura e da escrita conectando essas duas formas de enxergar o mundo, que segundo Pierre Levy e André Lemos - "O futuro da Internet: em busca de uma ciberdemocracia planetária".

O artigo "Meios digitais em práticas pedagógicas na educação: uma análise hermenêutica-fenomenológica”, de Azevedo (2016), usado na fundamentação teórica deste trabalho, expressa a interação entre os docentes frente às TDICs e como a troca de experiências entre eles permite maior intimidade com as tecnologias aplicadas a atividades pedagógicas de sucesso na aprendizagem discente. Sendo assim, o problema que norteia esta pesquisa circunda o multiverso das dificuldades observadas em crianças no processo de alfabetização e letramento, em especial as que estão fora da faixa de idade padrão, bem como a carência de metodologias que se utilizem das TDICs no processo em questão.

\section{METODOLOGIA}

Este trabalho desenvolveu-se parcialmente como pesquisa pura e parcialmente como aplicada, do tipo qualitativa, com objetivos descritivos e explicativos, uma vez que, em um primeiro momento, conta com um levantamento bibliográfico, artigos de Qualis A1 a B3; 
em um segundo momento, é feita uma análise crítica acerca de uma Sequência Didática (SD) aplicada com crianças fora da faixa de idade para alfabetização, na ONG Sinal Verde, Instituto Missão Integral.

\subsection{Métodos - a Sequência Didática}

Neste trabalho, a criação e a aplicação de SD se baseiam em projeto social vinculado à disciplina "Reforço Escolar" do Mestrado em Novas Tecnologias Digitais na Educação da UniCarioca, em parceria com sociedades civis (ONGs).

A SD programada contou com 3 horas de aplicação, divididas em seis etapas, compartimentadas em atividades analógicas, digitais e de expressão oral.

As etapas 1, 2 e 5 foram etapas digitais, e as etapas 3 e 4, analógicas; a etapa 6 trabalhou mais exclusivamente com a oralidade.

As etapas 1, 2, 3 e 4 consideram todos os níveis de aprendizagem dos alunos; já as etapas 5 e 6 consideram os níveis pré-silábico. A turma, porém, é mista, com crianças de 8 a 12 anos em disparidade idade-série, apresentando outros níveis de desenvolvimento, como silábico e alfabético. A turma se manteve integrada e comprometida em todas as atividades propostas.

As crianças sentaram-se em uma sala com mesas organizadas de forma circular, para facilitar a integração dos alunos, que puderam trabalhar com os seguintes recursos materiais: quadro branco, televisão ligada ao vídeo, letras em EVA, tablet com caderno digital instalado.

Esta SD objetiva oferecer aos educandos a oportunidade de tomar consciência do quanto e o que eles "sabem" ler (o semblante das pessoas, os rótulos dos produtos, as bandeiras dos times de futebol, os emojis - tão utilizados nos smartphones, a sinalização do trânsito, os textos escritos). Objetiva, também, analisar os códigos presentes no cotidiano, entendendo que tudo isso foi criado e pactuado pelos seres humanos para facilitar a comunicação e a interação social.

\section{1a Etapa - Tomada de Consciência}

Conversa informal sobre as diversas formas que existem de registrar nossos pensamentos, com a utilização e apresentação da SD HISTÓRIA DO ALFABETO_Aula1 Tomada de consciência.

Da Figura 1 até a Figura 4 ilustram a sequência em ordem cronológica de apresentação da esquerda para a direita, apresentando algumas páginas do caderno digital utilizados nesta etapa.

Figura 1 - Abertura

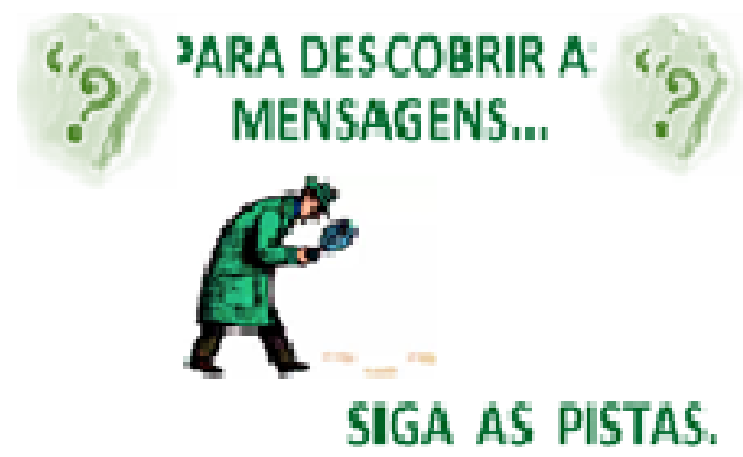

Fonte: Elaborada pelos autores (2019) 
Figura 2 - Qual o significado das imagens?

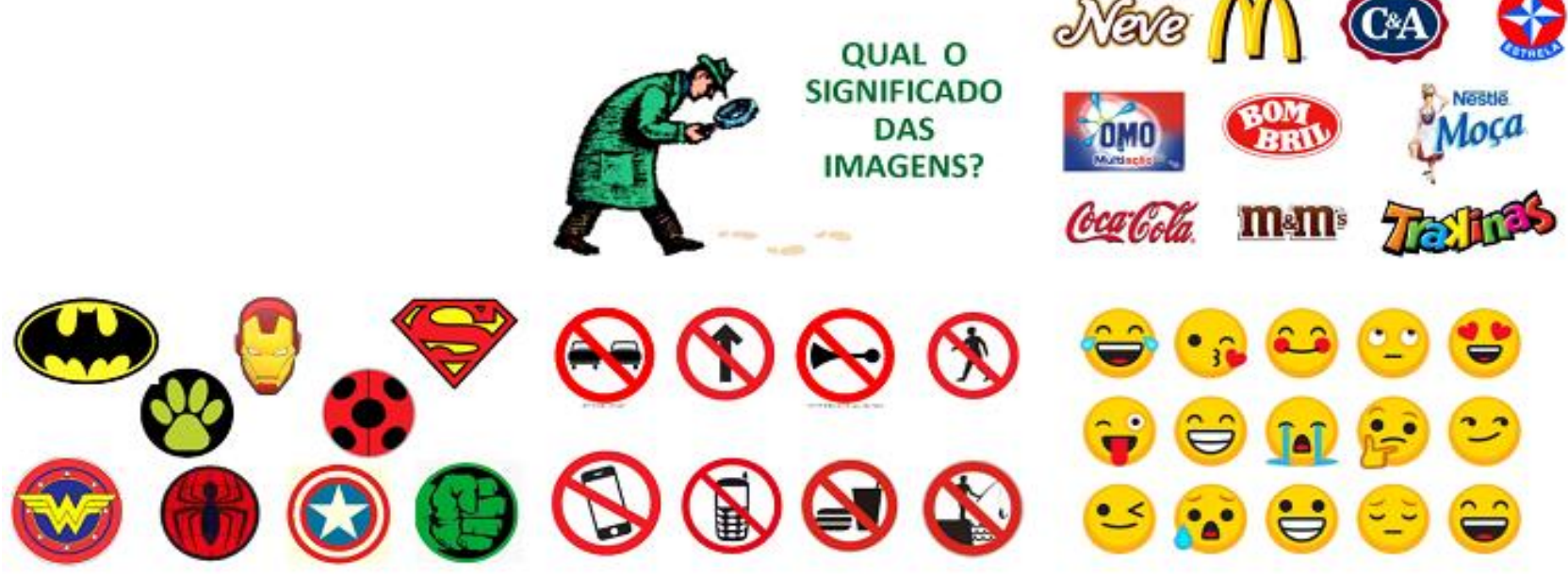

Fonte: Elaborada pelos autores (2019)

Figura 3 - O que está escrito aqui?
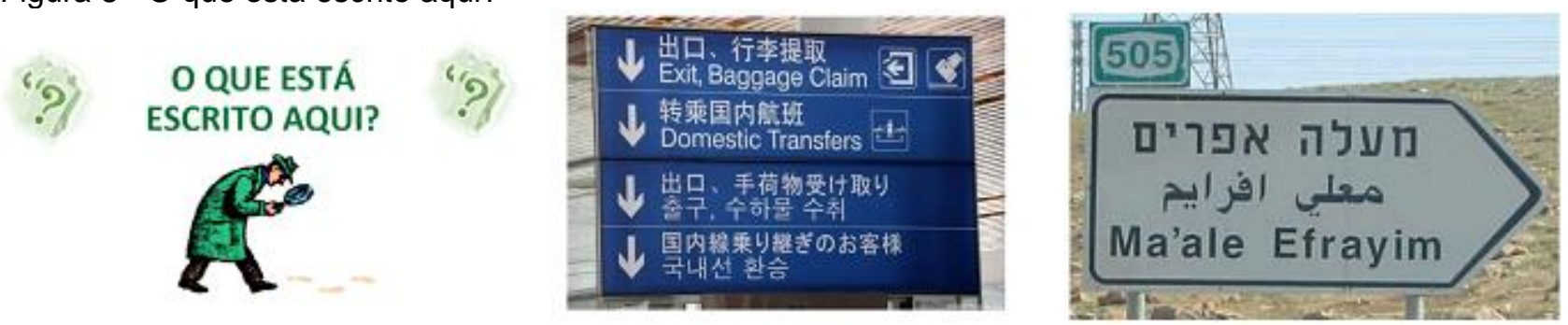

Fonte: Elaborada pelos autores (2019)

Figura 4 - Pessoas escrevem da mesma forma?
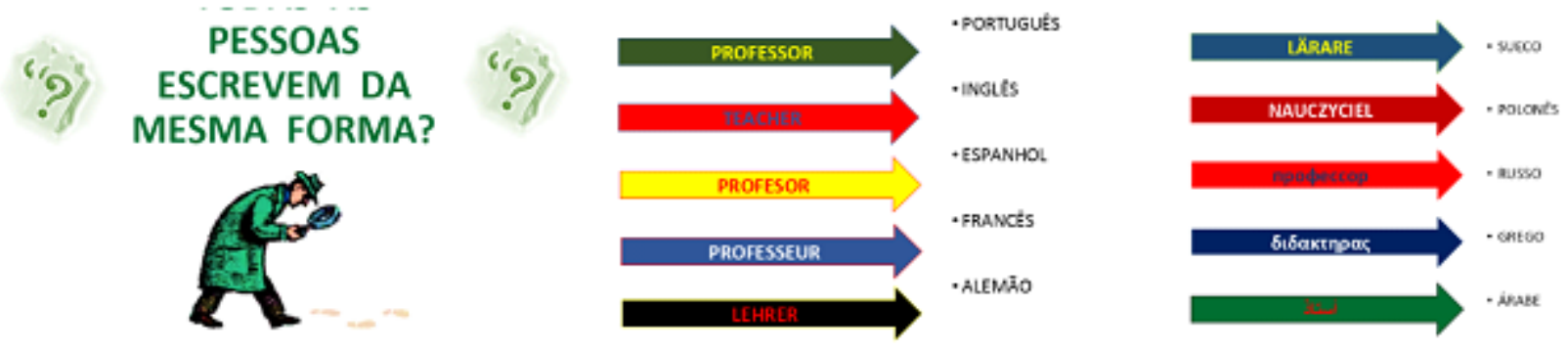

Fonte: Elaborada pelos autores (2019)

Objetivo: explorar a apresentação em pauta, fazendo com que os alunos falem sobre o que eles conhecem. Perguntar o que quer dizer cada símbolo que está na apresentação.

Habilidades - todas as fases: escutar, com atenção, as falas de professores e colegas, formulando perguntas pertinentes ao tema e solicitando esclarecimentos sempre que necessário (BNCC, 2018, EF15LP10); reconhecer os códigos presentes no cotidiano, identificando seus significados; reconhecer a existências de escritas diferentes, distinguir as letras do alfabeto de outros sinais gráficos.

\section{2a Etapa - Vídeo: Construção da escrita - parte 1}

Essa etapa, conta com a exposição do vídeo para as criancas a "Construção da Escrita - parte 1" que apresenta um pouco sobre a história deste processo ao longo dos tempos. 
Figura 5 - Print da tela do vídeo Construção da escrita no Youtube

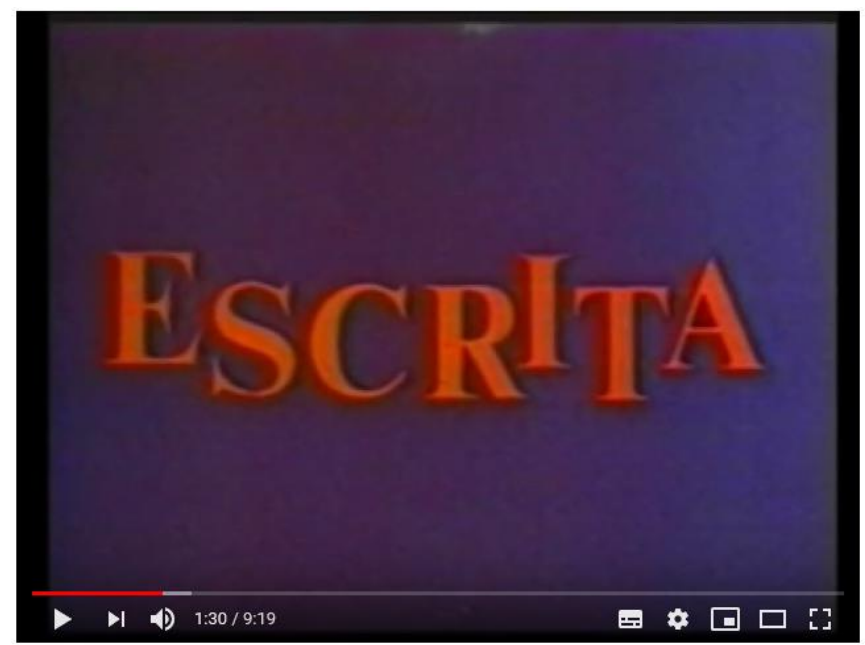

Construçao da escrita - parte 1

Fonte: Nova Escola - Módulo I do Programa de Formação de Professores Alfabetizadores (Profa), realizado pelo MEC em 2001.

1 - Pedir que os alunos prestem atenção ao vídeo sobre a história da escrita, buscando descobrir como surgiram as letras e os alfabetos.

2 - Ao final, perguntar o que eles descobriram sobre a escrita. Obs. Fazer algumas perguntas sobre o que eles viram.

Objetivo: Conversar sobre o tempo em que se escrevia na argila ou nas pedras, propondo perguntas tais como:

- Era possível ter livros?

- Todo mundo entendia o que estava escrito?

\section{3a Etapa - Brincar de Adivinha}

O método aqui era pedir que os alunos tentassem decifrar qual é o nome da criança que está no cartão. Utilizar apenas os cartões que contêm os nomes dos alunos do grupo (foi feito um cartão para cada um, formatando o nome dos alunos com a fonte Wingdings).

Primeiro, há que estimulá-los a descobrir o que está escrito, sem apresentar a tabela de correspondência letra-símbolo, depois repetir o processo com o auxílio da tabela.

Objetivo: levá-los a refletir sobre a necessidade de se conhecer o código para decifrar a mensagem.

\section{4a Etapa - Aplicativo Hieróglifo}

Objetivo: Escrever o próprio nome em hieróglifos, observando que o sentido da escrita é inverso ao nosso.

\section{5a Etapa - Caderno Digital}

As atividades do caderno digital são de interpretação de figuras e símbolos e compreendem, também, leitura e escrita.

Objetivo: pré-silábico; além dos exercícios de interpretação de imagens, existem exercícios para completar as palavras com as vogais e ligar o nome à figura. 
Da Figura 6 até a Figura 9 ilustram a sequência em ordem cronológica de apresentação da esquerda para a direita, apresentando algumas páginas do caderno digital utilizados nesta etapa.

Figura 6 - Interpretação de imagens e símbolos

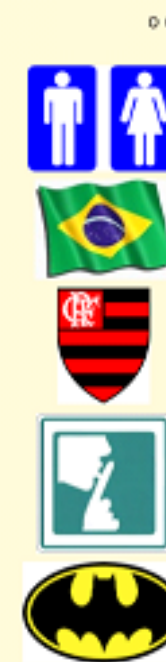

D QUT ESSMS DYNGTNS AEPRESENTAM?

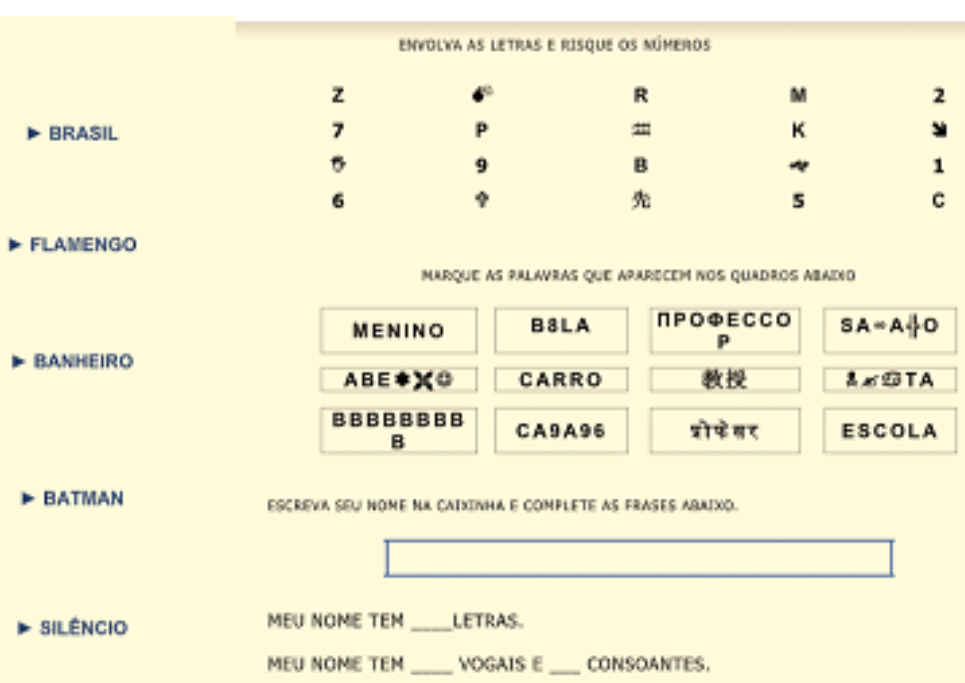

Fonte: Elaborada pelos autores (2019)

Figura 7 - Interpretação de imagens e símbolos, correlação com a escrita

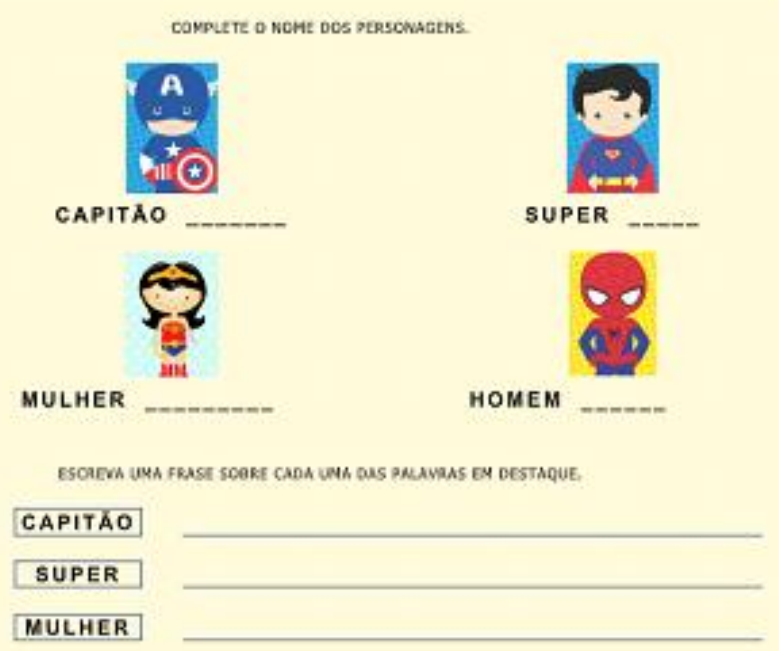

COPE AS PMUARUS QUE REPRESEVTAM O SIONOICADO COS GESTOS A SEGUIR.
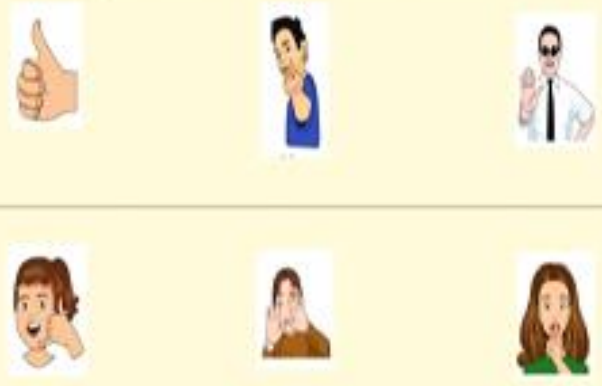

SILENCIOI

PARE CERTO TELEFONA! VEM!

1 I

Fonte: Elaborada pelos autores (2019) 
Figura 8 - Interpretação de imagens e símbolos, correlação com a escrita

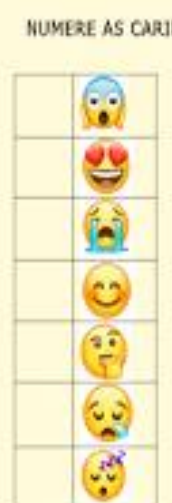

1. FELIZ

2 - APAIXONADO

3. ASSUSTADO

4- CHORANDO

5 - TRISTE

6 - PENSATIVO

7 - DORMINDO
CS hótulos a secur. peatences a que mocutost
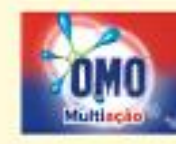

PMELL HISIRICO

seskio En PO

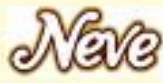

ACHOCELATABO

serknotunte

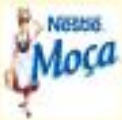

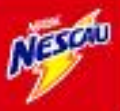

cacicta

SABONETE secounentavisueos

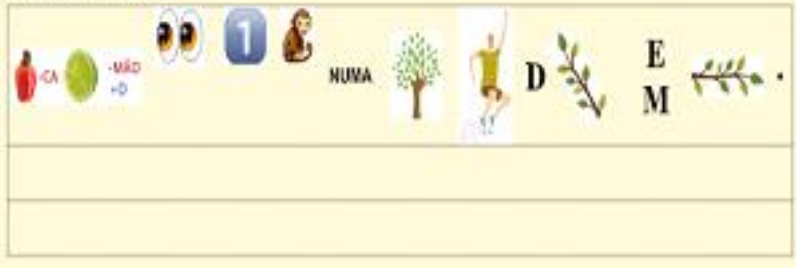

0 药

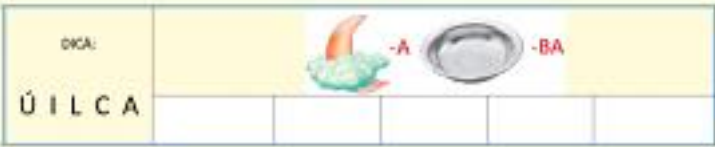

Fonte: Elaborada pelos autores (2019)

Habilidades - todas: ler e interpretar imagens e textos.

Reconhecer que textos são lidos e escritos da esquerda para a direita e de cima para baixo da página.

Distinguir as letras do alfabeto de outros sinais gráficos. Identificar fonemas e sua representação por letras (A13:A15).

Relacionar elementos sonoros (sílabas, fonemas, partes de palavras) com sua representação escrita. Reconhecer o sistema de escrita alfabética como representação dos sons da fala. 
Figura 10 - Tabela explicativa sobre a Psicogênese da Língua Escrita.

AVALIAÇÃO DA ESCRITA (Ferreiro \& Teberosky, 1991)

\begin{tabular}{c|c|l}
\hline Número de pontos & Nivel da escrita & \multicolumn{1}{c}{ Caracteristicas } \\
\hline 4 & Nivel alfabético & $\begin{array}{l}\text { Cada um dos caracteres da escrita corresponde a } \\
\text { valores sonoros menores que a silaba. Não atende à } \\
\text { norma ortográfica. }\end{array}$ \\
\hline 3 & $\begin{array}{c}\text { Nivel silábico- } \\
\text { alfabético }\end{array}$ & $\begin{array}{l}\text { Manifestação alternante do valor silábico ou fonético para } \\
\text { as diferentes letras. }\end{array}$ \\
\hline 2 & Nivel silábico & $\begin{array}{l}\text { Cada letra vale por uma silaba. Escrita com ou sem o } \\
\text { predominio do valor sonoro convencional. }\end{array}$ \\
\hline 1 & $\begin{array}{c}\text { Nivel prè- } \\
\text { silábico }\end{array}$ & $\begin{array}{l}\text { Marcado por escritas que não apresentam nenhum tipo } \\
\text { de correspondência sonora, isto é, sem relação com } \\
\text { grafia e som. }\end{array}$ \\
\hline 0 & Somente rabiscos. \\
\hline
\end{tabular}

Fonte: Psicogênese da Língua Escrita. 3. ed. Porto Alegre: Rio Grande do Sul, Artmed, 1999.

\section{6⿳亠口冋 Etapa - Avaliação}

Cada aluno deverá responder às perguntas feitas pelo professor. Essas perguntas deverão levar os alunos a falarem sobre o que aprenderam, de que gostaram, de que não gostaram, o que foi difícil, o que foi fácil.

Objetivo: auxiliar o aluno a tomar consciência do que foi aprendido, de suas dificuldades e de seu potencial; auxiliar o professor a planejar as próximas atividades.

A aplicação das SDs divide-se em quatro momentos importantes para manter o interesse do grupo e a capacidade de desenvolver aspectos cognitivos e afetivos simultaneamente.

Apresentar o vídeo resgata o histórico da atividade, trazendo memórias de outras gerações fazendo a ligação com fatos atuais referentes ao uso social da escrita.

A aplicação de atividades envolvendo rimas e adivinhas partindo das palavras que são identificadas com facilidade pelas crianças, potencializa a identificação e a aprendizagem significativa. É importante a mediação dos educadores para integrar os diferentes níveis pré-silábico, silábico, silábico alfabético e alfabético, mantendo o interesse do grupo. Foi perceptível a empolgação das crianças nesta etapa.

Trazer os hieróglifos foi bem interessante, porque as crianças perceberam a utilização inversa da nossa escrita e uma maneira diferente de visualizar as palavras.

O Caderno Digital é o clímax da atividade; percebe-se que as crianças, como nativos digitais, identificam-se bastante com o uso das tecnologias.

\section{ANÁLISE E DISCUSSÃO DOS RESULTADOS}

Segundo Santiago (2016), atividades didáticas devem apresentar correlações diretas com as bases freireanas que trabalham um método de alfabetização baseado nas experiências de vida das pessoas.

Paulo Freire (1921 - 1997) deixou grande legado no cenário educacional, conseguindo provar que a alfabetização começa com a tomada de consciência por parte do educando, entendendo-se pertencente ao todo cultural que envolve o grupo social. 
A ação educativa libertadora estabelece uma relação horizontal entre os parceiros culturais. Na alfabetização de crianças, faz-se necessário esse olhar humanizado e esperançoso, que faz parte do corpo teórico descritivo das ações freireanas.

A perspectiva que parte do pressuposto de uma compreensão e conscientização do mundo e da realidade social possibilita ao aluno a aprendizagem da leitura e da escrita de forma mais concreta, estabelecendo uma reflexão crítica e compreensão do mundo.

A Psicogenética (Emília Ferreiro estudou os mecanismos pelos quais as crianças aprendem a ler e escrever. De acordo com este referencial, a apropriação da escrita se apoia nas hipóteses (pré-silábica, silábica, silábico-alfabética e alfabética) dos aprendizes e estas revelam informações sobre os níveis do processo de alfabetização) ainda considera a aprendizagem da criança por meio de suas hipóteses, em que é proposto um planejamento e avaliações baseadas nas reais necessidades, vinculando a utilização da Sequência Didática às concepções freireanas, as quais, segundo Santiago, devem ser preservadas na prática educativa significativa. Isso ocorre pela necessidade de gerar, no discente, a compreensão e conscientização do mundo e da realidade social em que se insere, possibilitando a aprendizagem da leitura e da escrita de forma mais concreta, de modo que o indivíduo estabeleça uma reflexão crítica do mundo.

Segundo Tezani (2017), são descritas alterações no comportamento dos estudantes, correlacionadas também a grandes transformações nas esferas de valores e atitudes sociais. Os recém-batizados de "nativos digitais", pelos autores citados, podem ser descritos como aqueles que se utilizam constantemente das TDICs, principalmente através de dispositivos móveis, como tablets e celulares.

Então, os nativos digitais apresentam intensa relação com o uso de computadores, games e videogames conectados ao ciberespaço; portanto devem ser capazes de levantar informações e processar o recebimento de tudo que advém dessa interação com mais rapidez.

Segundo Beirão (2018), em seu trabalho "O uso de TDIC nos anos iniciais da educação básica para aprendizagem", o uso de TDICs como ferramenta pedagógica para o processo de alfabetização e letramento é de grande valor, uma vez que se apresenta como um recurso atrativo e interativo. Portanto, a SD utilizada apresenta diversas atividades que contam com o uso da ferramenta digital para promover o encantamento no público-alvo, necessário ao desenvolvimento das habilidades referentes à fase présilábica.

(...) por ser um instrumento tão diversificado, pode-se tê-lo como um recurso na nossa prática pedagógica, estimulando o desenvolvimento da criança em todas as áreas do conhecimento. A criança se apropria de tal forma do computador que este faz parte de sua vida, como mais uma maneira de adquirir conhecimento. (MELLO, 2004, p. 172)

Uma das vantagens da aplicação de atividades pedagógicas que envolvam o uso de TDICs é que elas podem se mostrar inéditas, com um conjunto de novidades e sentimentos motivacionais envolvidos, instigando o processo de busca de informações e a atenção dos estudantes. Para Beirão (2018), "uso desses recursos, usados de forma apropriada, fará com que o educador consiga explorar o aluno em milhões de maneiras, fazendo com que eles se superem e que possam ir além do que acham que são capazes".

Na visão de Freire (2012, p.187), "os fenômenos da experiência humana são fonte inesgotável de investigação, interpretações e reinterpretações"; assim sendo, dificultam o desvendar dos fenômenos em sua totalidade. Logo, a aplicação desta SD pelos investigadores, autores deste trabalho, proporciona a investigação do fenômeno in loco, 
ou seja, promove a verificação de etapas cruciais no processo de construção e sedimentação do conhecimento ou habilidade que se apresenta ao grupo.

O presente trabalho traz, a partir deste ponto, a reflexão crítica, apoiada em alguns dos temas hermenêutico-fenomenológicos, da aplicação da sequência didática (SD) com foco na alfabetização mediada em Novas Tecnologias Digitais. Os temas utilizados para tecer as críticas são dispostos em ordem cronológica, de acordo com o desenvolvimento. Portanto, são comentados os seguintes temas: Abertura, Desafio e Compromisso. Destacam-se, neste trabalho, dentro do tema Compromisso, os subtemas Barreiras, Resultado e Cooperação.

Iniciando a análise, retomamos com as ideias de Azevedo (2016) para discorrer o tema Abertura:

[...] a abertura é uma atitude interior, uma Abertura para si, para o outro e para o meio. Abertura para o novo, para o diferente, para a participação efetiva do aluno, conduz a uma busca constante dos docentes por Sintonia. [...] A amplitude desses significados é bem profunda, pois sempre requer a participação ativa das partes envolvidas. Estar em sintonia implica estar em igualdade de frequência numa relação de acordo e correspondência. [...] Desta forma, para estar em Sintonia com o mundo contemporâneo e com seus alunos, esses professores buscam uma aproximação com o universo dos alunos, com suas linguagens, com os aparatos tecnológicos que os cercam cotidianamente.

As etapas descritas nos métodos de aplicação da Sequência Didática apresentada no item anterior buscaram esta abertura, sintonia e aproximação, trazendo o estudante para a vontade de se conectar com o novo, abrindo o olhar para as possíveis informações que ali seriam trabalhadas. A ludicidade que envolveu tanto a parte analógica quanto a digital permitiu que este objetivo fosse atingido, pois foram pensadas levando em consideração o universo destes alunos, classe de alfabetização tardia, já que se trata de crianças de 8 a 12 anos.

Os autores acreditam na concretização desta abertura, uma vez que, tanto as crianças do fase pré-silábica quanto das outras fases mostraram-se encantadas e motivadas com as atividades que Ihes eram apresentadas e que realizavam com aparente envolvimento.

O tema Compromisso com a aprendizagem do aluno e o desenvolvimento de suas habilidades é parte do processo educativo, como bem defendera Freire. Para uma educação transformadora, faz-se indispensável pensar em aproximar o conhecimento e a aplicação prática no seu cotidiano, libertando o sujeito da condição de oprimido a partir de sua capacidade transformadora e criativa, relacionada a cada um de seus atos.

A ferramenta primordial do processo de libertação será sempre na prática do diálogo. Assim, durante toda a proposta criativa e de aplicação da SD em questão, esse diálogo é fomentado, pensado pelos professores de forma minuciosa e aplicado com seriedade e compromisso, considerando o caráter misto da turma no que tange à alfabetização.

A SD apresentou elementos de promoção e fomento ao diálogo, desde as figuras escolhidas, jogos e brincadeiras promovidas, às questões âncora e de avaliação, que visavam o tempo todo indicar que a opinião dos aprendentes era necessária ao desenvolvimento de sua aprendizagem.

As crianças da fase pré-silábica respondiam quando solicitadas, procuravam questionar quando sentiam necessidade e o mesmo se observou nas outras duas fases.

O tema Barreiras, não poderia deixar de ser analisado, tanto no processo de produção da SD, como em sua aplicação. Há tempos, pesquisadores e professores procuram superar barreiras vinculadas a práticas obsoletas, desestimulantes, práticas que 
trabalham apenas com o simples e descomprometidas com todo um universo psicossocial existente na realidade do aluno.

Segundo Azevedo (2016), há barreiras impostas, muitas vezes, por um sistema educacional que, no discurso, valoriza o uso das TDICs, mas que ainda mostra essa prática como algo muito distante. Diversas vezes, os entraves que fomentam essas barreiras são de ordem técnica, como ausência de wi-fi para os alunos e professores em instituições escolares.

Não obstante, para muitos docentes, o interesse por fugir do tradicional e buscar motivar seus estudantes, mesmo com as barreiras apresentadas, permanece, ou seja, 0 entusiasmo é mantido mesmo com as adversidades infraestruturais ou pedagógicas.

A instituição visitada, no caso específico desta pesquisa, enfrenta barreiras imensas, tais como tecnologia limitada e apoio apenas de algumas instituições parceiras; porém, a abertura para a pesquisa permite o acesso dessas crianças a entusiastas da educação, cuja prática pedagógica apresenta uma proposta inovadora e eficaz no que tange à aprendizagem.

A aplicação da SD contou com todas essas barreiras para sua estruturação, mas os professores da aplicação sabiam de sua existência e foram preparados para contornar o que fosse surgindo, conseguindo aplicar as atividades programadas, dentro do tempo estipulado, mantendo os objetivos estruturados.

Azevedo (2016) destaca o tema Resultado, que "[...] é o que inspira esses docentes a seguirem em frente, e nesse processo seguem atendendo ao Desafio de fazer uma docência diferenciada em sintonia com o século XXI". A perspectiva de um Resultado que se concretiza de uma aprendizagem compartilhada, só ocorre através de uma vivência de experiências entre professor e alunos, alunos entre si, e a confiança que se estabelece a partir destas relações.

Como resultados da aplicação da SD, destacamos a troca coletiva, a motivação discente, o processo de encantamento vivenciado por estes e as experiências coletadas a partir desta aplicação pelos docentes pesquisadores envolvidos.

Comprovou-se, na prática, ser possível o que defende PORTO (2012, p.192): "As TDICs na escola devem ser usadas para superar o senso comum pedagógico e para efetivar uma pedagogia condizente com as necessidades de um ensino contextualizado num tempo e num espaço de ser, viver, interagir e criar."

\section{CONSIDERAÇOES FINAIS}

Seria ingênuo e utópico por parte destes pesquisadores afirmar que todos os objetivos foram alcançados; porém, o levantamento bibliográfico apresentou um repertório de conceitos que incentivam o prosseguimento desta pesquisa. As leituras apoiam o uso de TDICs em práticas pedagógicas, como ocorreu com a Sequência Didática programada e aplicada, tal como analisado neste estudo, e reforçam os conceitos hermenêuticofenomenológicos de Freire, como os também apresentados nos trabalhos de Azevedo (2016).

No que se refere a construção de objetos de conhecimentos com uso de TDICs como ferramenta pedagógica, trazendo para sala de aula esse universo de cibercultura, imerso ao cotidiano dos alunos, percebeu-se imediata motivação à participação das atividades propostas, interatividade, colaboração entre os estudantes, o que ratifica o que a academia vêm demonstrando, que metodologias e práticas didáticas que fomentam 0 uso dessas diferentes tecnologias favorece os processos de ensino e aprendizagem. 
Para que os objetivos conceituais ligados ao desenvolvimento das competências que envolvem o processo de alfabetização fossem plenamente alcançados, seria necessário que houvesse mais visitas por parte dos pesquisadores para a aplicação de novas SDs pensadas e projetadas a partir das experiências vividas até o presente momento. Com isso, constata-se que muito ainda há que ser feito no que tange à reformulação de práticas pedagógicas vinculadas às demandas sócio-históricas do século $\mathrm{XXI}$, o que de fato nos motiva a continuar a enriquecer nossas pesquisas e práticas pedagógicas.

\section{REFERÊNCIAS}

AZEVEDO, A. B. de. Meios digitais em práticas pedagógicas na educação: uma análise hermenêutica-fenomenológica. Educação. Revista do Centro de Educação, vol. 41, núm. 2, mayo-agosto, 2016, pp. 495- 507. Disponível em:

<http://www.redalyc.org/articulo.oa?id=117146405018>. Acesso em: 24 maio de 2019.

BEIRÃO, K. C. C. S. O uso de TDIC nos anos iniciais da educação básica para aprendizagem. CIET: EnPED, 2018.

BINOTTO, C.; ANTUNES, R. S. Tecnologias digitais no processo de alfabetização: analisando o uso do laboratório de informática nos anos iniciais. Universidade Federal do Paraná, 2014.

DEMO, P. Conhecimento, tecnologia e formação dos professores das séries iniciais. REUNIÃO ANUAL ANPEd, GT, 2000.

DIAS, C. M.; FARBIARZ, J. L. Jogos como gêneros multimodais: análise e elaboração crítica para multiletramentos. Educação (UFSM), v. 44, p. 14-1-28, 2019.

FERREIRO, E. Alfabetização em processo. 12. ed. São Paulo: Cortez, 1998. 144p.

FERREIRO, E. Com todas as letras. São Paulo: Editora Cortez, 1993. 4. ed. 102 p.

FERREIRO, E.; TEBEROSKY, A. Psicogênese da Língua Escrita. 3. ed. Porto Alegre: Rio Grande do Sul, Artmed, 1999.

FREIRE. M. M. Da aparência à essência: a abordagem hermenêutico-fenomenológica como orientação qualitativa de pesquisa. In: ROJAS, J.; STREINGHETA, L. M. (Orgs.).

Educação, pesquisa e prática docente em diferentes contextos. 1. ed. São Paulo: Life Editora, 2012.

FREIRE, P. Pedagogia do oprimido. 12. ed. Rio de Janeiro: Paz e Terra, 1983.

Educação como prática da liberdade. 15. ed. Rio de Janeiro: Paz e Terra, 1983b.

HENDEL, G. do N. Letramento digital: o uso do tablet como recurso móvel facilitador da alfabetização e do letramento. Colóquio Luso-Brasileiro de Educação-COLBEDUCA, v. 2, 2017.

MOREIRA, W. Q. B. B. Análise de software educativo para alfabetização de crianças. 157 f. Dissertação apresentada ao curso de mestrado profissional em computação aplicada da Universidade Estadual do Ceará (UECE). Fortaleza, 2014.

PALFREY, J.; GASSER, U. Nascidos na era digital: entendendo a primeira geração dos nativos digitais. Porto Alegre: ARTMED, 2011. 
PORTO, T. M. E. As tecnologias estão na escola. E agora, o que fazer com elas? In:FANTIN, M.; RIVOLTELLA, P. C. Cultura digital e escola: Pesquisa e Formação de professores. PapirusEditora: Campinas, SP., 2012.

PRENSKY, M. From digital nativesto digital wisdom: hopefulessays for 21st Century learning. Thousand Oaks: Corwin, 2012.

PRENSKY, M. Aprendizagem baseada em jogos digitais. São Paulo: Senac, 2001.

SANTIAGO, L.; DIONISIO, M.; SAMPAIO, R. O uso das Tecnologias Digitais na busca da superação do analfabetismo. In: Anais dos Workshops do Congresso Brasileiro de Informática na Educação. 2016. p. 800.

SOARES, M. Novas Práticas de leitura e escrita: letramento na cibercultura. Educ. Soc., Campinas, vol. 23, n. 81, p. 143-160, dez. 2002. Disponível em:

<http://www.scielo.br/pdf/es/v23n81/13935.pdf>. Acesso em: 24 maio de 2019.

TEBEROSKY, A.; COLOMER, T. Aprender A Ler E a Escrever: Uma proposta construtivista. Porto Alegre: Artmed, 2003.

TEZANI, T. C. R. Nativos digitais: considerações sobre os alunos contemporâneos e a possibilidade de se (re) pensar a prática pedagógica. DOXA: Revista Brasileira de Psicologia e Educação, v. 19, n. 2, p. 295-307, 2017.

VYGOTSKY, L.S. Linguagem, desenvolvimento e aprendizagem. São Paulo, 1998. 